\title{
Honestly, why are you driving a BMW?
}

\author{
Olof Johansson-Stenman and Peter Martinsson \\ Department of Economics, Göteborg University"
}

\begin{abstract}
This paper proposes that people derive utility not only from goods or their attributes as in standard models, but also from their self-image as influenced by their own perception of their preferences. In a representative survey, most respondents considered their own concern for status when purchasing a car to be minor in comparison with the status concerns of others. Similarly, most individuals considered themselves to be more environmentally concerned than other people. These results are consistent with an extension of the conventional theory where an individual's selfimage is added as an argument in the utility function.
\end{abstract}

\section{JEL classification: A13, D12}

Key words: Status, environmental concern, self-deception, self-image, preference falsification.

\footnotetext{
${ }^{\#}$ Corresponding author: Olof Johansson-Stenman, Department of Economics, SE-40530 Göteborg, Sweden. Tel.: +46 77325 38; fax +46 77310 43. E-mail address: olof.johansson@economics.gu.se.

Acknowledgements: We are grateful for useful comments from Fredrik Carlsson, seminar participants at Göteborg University, conference participants at Transport Forum, Linköping, and in particular an anonymous associate editor. Financial support from the Swedish Agency for Innovation Systems (VINNOVA) is gratefully acknowledged.
} 


\section{Introduction}

Do you know your own preferences perfectly? To some economists such a question may seem odd. How else can we make choices? To psychologists, on the other hand, the question is generally seen as both meaningful and adequate, and they often conclude that we do not know our own preferences perfectly. Slovic (1995), for example, argues that we only know our preferences for a few well-known goods and that we must consequently construct our preferences for other goods when needed. Correct or not, after a moment of reflection, most probably agree that with our limited cognitive ability we are not even able to explain our complete preferences to ourselves. From a scientific point of view, however, a more important issue is whether the deviation between our preferences on the one hand and our perception of our preferences on the other is purely stochastic, or whether there are systematic elements that can be explained. Investigation of this issue is the primary aim of the current paper.

In doing so, a simple model is developed which attempts to explain possible differences between perceived and actual preferences. The most crucial assumption in the model is that people derive utility from having a good self-image, or identity, and that they therefore behave and interpret reality so as to maintain or improve such an image. This model is then tested by utilizing an anonymous survey where a representative sample of Swedes were asked how much a variety of characteristics, including status value and environmental performance, would matter when they themselves, as well as others, are about to buy a car.

Most people want to give a good impression and be perceived as complying with various social norms in order to gain social approval and esteem. Hence, we have 
a personal interest in pretending to behave 'better', or more in accordance with (possibly local) existing social norms, than we actually do; we may for example exaggerate our social responsibility, or modify our musical taste, in the presence of others. Kuran (1995) discusses such "preference falsification" to obtain social acceptance in depth, and presents overwhelming evidence that preference falsifications are important for much of human behaviour. This is therefore taken as a point of departure in the present paper. For example, if it is considered politically correct to be concerned about the environment, then people have an incentive to overstate their own concern when communicating with others. A possible consequence of this is that people may believe that others are more environmentally concerned than they actually are.

However, in addition to social norms (see e.g. Elster 1989 and Young 1998 for overviews), which we try to fulfil through modified self-presentation in order to obtain social acceptance, there are also personal norms, which we try to comply with even when our behaviour is not observable by others (see e.g. Aaron 1994, Kuran 1998a). One reason for this is that we like to improve or maintain a positive selfimage. In this paper we focus largely on self-image effects obtained from our own perception of our preferences, which are analyzed through an anonymous survey.

Brekke et al. (2002) propose a model where people contribute to public goods in order to improve their self-image. The model was backed-up by Norwegian surveyevidence regarding people’s motivation for re-cycling: As many as 73\% agreed that one of their reasons was that they would like to see themselves as responsible people. Otherwise direct empirical evidence is rather scarce. But while still uncommon in economics, ${ }^{1}$ it is considered almost self-evident in social psychology that people care

\footnotetext{
${ }^{1}$ There is a small but rapidly growing economics literature on economics and self-image (or identity),
} 
about their self-image (e.g. Baumeister, 1998), and that they interpret reality, including their own characteristics, in order to maintain or improve their self-image. Hence, the standard view in social psychology nowadays (as opposed to some decades ago) is not that people have an unbiased view of themselves, but rather that they engage, unconsciously or subconsciously, in a degree of self-deception (Taylor and Brown, 1994). ${ }^{2}$

Presumably, being motivated largely by status concerns is perceived to be an unfavorable trait of character by many. This may imply that self-reported concerns for status would be systematically biased downwards. Similarly, self-reported concern for attributes signaling social responsibility, such as environmental friendliness, might be biased upwards. To test whether self-deception to improve their self-image plays a role, as suggested by social psychologists, we asked the respondents to say how they thought that others (identified either as others in their neighborhood or as the average Swede) would, on average, value the same characteristics when buying a car. If selfdeception does play a role, we would expect people to respond that they themselves are less concerned with status and more concerned about the environment than most people. We also asked the same questions to a sample of car dealers to obtain more including Loewenstein (1999), Akerlof and Kranton (2000, 2002), Brekke and Howarth (2000), Köszegi (2001), Benabou and Tirole (2002, 2003), and Johansson-Stenman and Svedsäter (2003).

${ }^{2}$ Although some people have unrealistically negative images of themselves as well, there is much empirical evidence that the general picture is the opposite. This does not prevent people from handicapping themselves or behaving self-destructively, however. Consider a student facing a hard exam tomorrow. He doubts that he will pass it, even if he studies hard. If he parties all night his chances will of course be further reduced. However, if he does he can blame the bad exam results on partying. If he instead studies hard, and fails, he may doubt his own intellectual ability, which is much worse. 
unbiased responses, since part of their success as dealers depends on their ability to judge what characteristics people really care about when they are purchasing a car. Similar biases, but possibly to a lesser degree, may of course also exist for other attributes such as motor power and safety.

A secondary aim of this paper is to contribute to the relatively small empirical literatures on status concern, and environmental concern, respectively. There is a substantial body of mainly theoretical economics research on consumption and status; see Frank (1985a, b, 1999), Weiss and Fershtman (1998), Holländer (2001) and Brekke and Howarth (2002) for useful overviews. Hirsch (1976), Frank (1985a, b, 1999) and others suggest that some goods are more positional than other goods. In particular, it has been assumed that visible goods such as houses, cars and jewellery, and more generally goods that effectively signal a desirable characteristic of the owner, are more positional than other goods, i.e. that the relative consumption in comparison with others is more important for these goods. For example, an expensive good may signal wealth, and indirectly it may also signal a high level of competence or ability. ${ }^{3}$

Using revealed-preference consumption data to investigate status concern is difficult as most goods are comprised of many attributes and the status effect is typically difficult to disentangle. Kooreman and Haan (2001) showed that people have a non-negligible willingness to pay for a license plate that signals that the car is newer than it would be perceived to be with another plate; Chao and Schor (1998) showed that the price-quality correlation is much weaker for more visible types of cosmetics

\footnotetext{
${ }^{3}$ However, in an anti-materialist sub-culture, consumption of certain types of simple and inexpensive goods may instead generate status, signalling that the individual is concerned with higher values rather than material ones.
} 
products, indicating a higher status premium; whereas Basmann et al. (1988) found that US expenditure data divided on different consumer goods are consistent with Veblen's (1899) theory of conspicuous consumption. In stated-preference studies, Solnick and Hemenway (1998) and Alpizar et al. (2002) compared the degree of positionality for different goods and found, as expected, that more visible goods (such as cars) tend to be more positional. The current paper contributes to this literature by showing how different socio-economic variables affect how important status is perceived to be, for oneself and others, when buying a car.

That many people also care about their own contribution to environmental degradation is evident from observed consumer choice, and the associated advertising, where a non-negligible fraction of consumers are willing to pay a premium for goods that are considered environmentally friendly; see Ewing and Sarigöllü (1998), Brownstone and Train (1999), and Brownstone et al. (2000) for stated-preference evidence regarding choice of cars. ${ }^{4}$ Furthermore, recycling activities are performed on a large scale in many countries even when there are no or poor financial incentives to do so; see e.g. Ackerman (1997) and Brekke et al. (2002). As for status concern, this paper contributes to the literature by measuring how perceived environmental concerns vary among different socio-economic groups.

The rest of the paper is organized as follows: Section 2 presents a simple rational-choice model where self-image is an argument in the utility function, while Section 3 describes the survey and presents descriptive results. Econometric analysis is provided in Section 4, followed by conclusions in Section 5.

\footnotetext{
${ }^{4}$ For some goods, such as food and hygiene products, part of this may of course be explained by believed health effects rather than environmental concern.
} 


\section{The Model}

To formalize the idea that self-image matters, we assume a Lancastarian model where the utility depends on a vector of attributes $a=\left\{a_{1}, \ldots, a_{n}\right\}$ rather than goods per se, and where the attributes depend on a vector of consumer goods $x$. In addition, we include self-image (or identity perception) $S$ as an argument in the utility function which then takes the following form:

$$
U=u(a, S) \equiv u\left(a_{1}(x), \ldots, a_{n}(x), S\right) .
$$

This is quite similar to the formulations in Akerlof and Kranton $(2000,2002)$ and Johansson-Stenman and Svedsäter (2003). However, Akerlof and Kranton use the identity concept largely to explain why people behave differently in similar circumstances, in order to identify why some social categories differentiate themselves from others, and when different individuals would like to associate with different categories. For example, while many men derive additional utility from working in a typical male job, the opposite holds for many women. Here, on the contrary, the focus is on self-image elements that most, if not all, people share to different degrees. Presumably, most people's self-image depends positively on personal characteristics such as honesty, intelligence, friendliness, social responsibility and beauty; and negatively on jealousy, shallowness, stinginess, selfishness and anger. Hence, we derive utility from seeing ourselves as honest, socially responsible, beautiful etc., as is typically put forward in the modern literature on cognitive dissonance; see e.g. Akerlof and Dickens (1982), Aronson (1992), and Rabin (1994). ${ }^{5}$ The perception of the degree to which these personal characteristics

\footnotetext{
${ }^{5}$ As discussed in this literature, characteristics such as beauty and social responsibility are subjective. This means that we can not only modify our perceptions so as to see ourselves as more socially responsible, we can also modify our perceptions of how a socially responsible person behaves so that
} 
apply to ourselves can, in turn, be affected by the perceptions of which of these goods attributes we consider to be important. For example, being concerned with the status conferred by a car may indicate shallowness and jealousy, whereas concern for an environmentally friendly car may indicate social responsibility. Then we can write a reduced form of the self-image function as dependent on the perception $\hat{a}$ of the attributes that we value. Still, as noted e.g. by Elster (1999, ch. 5) and Benabou and Tirole (2002), there is a limit to self-deception. Here we will not model that limit as a restriction, but rather as a part of the overall optimisation; we will simply assume that people’s self-image also depends on the degree of honesty they have with themselves. This formulation is similar to the one in Kuran (1987, 1990, 1995), with one important difference: In Kuran’s model, people feel dishonest because they falsify their preferences to others. Here people feel dishonest because they bias their perception of their own preferences away from their 'actual' preferences. ${ }^{6}$ For example, if we never re-cycle our garbage and drive an extremely high-polluting car, we may feel dishonest to ourselves if we claim to ourselves (e.g. when answering an anonymous survey) that environmental performance is a very important attribute when buying a car. Formally we then have:

$$
S=s(\hat{a}, h(d)) \equiv s\left(\hat{a}_{1}, \ldots, \hat{a}_{n}, h\left(d_{1}, \ldots, d_{n}\right)\right) \equiv s\left(\hat{a}_{1}, \ldots, \hat{a}_{n}, h\left(\left|\hat{a}_{1}-a_{1}\right|, \ldots,\left|\hat{a}_{n}-a_{n}\right|\right)\right),
$$

where $h$ is a measure of honesty which depends negatively on the vector $d$ of discrepancies between the perceived and the true attribute importance, $\hat{a}-a ;||$ denotes absolute value. Substituting (2) into (1) implies

$$
U=u\left(a_{1}(x), \ldots, a_{n}(x), s\left(\hat{a}_{1}, \ldots, \hat{a}_{n}, h\left(\left|\hat{a}_{1}-a_{1}(x)\right|, \ldots,\left|\hat{a}_{n}-a_{n}(x)\right|\right)\right)\right) .
$$

they are closer to how we typically behave ourselves. For analytic simplicity, we disregard such effects in the model, however.

${ }^{6}$ That is, the preferences they would have when disregarding self-image effects. 
The individual is assumed to maximize this expression with respect to the consumption vector $x$, as well as the perception-of-attribute vector $\hat{a}$. However, in a survey-context the choice of $x$ is clearly given, and will not be affected by the stated preferences for the importance of different attributes. Hence, maximization of (3) in a survey context implies the maximization of (2). The first order condition with respect to $\hat{a}_{i}$ implies

$$
-\frac{\partial s}{\partial \hat{a}_{i}}=\frac{\partial s}{\partial h} \frac{\partial h}{\partial d_{i}}
$$

Assume that self-image depends negatively on the perceived status concern $\hat{a}_{i}$, and positively on honesty $h$, which in turn depends negatively on the (absolute value of the) deviance from the respondent's true status concern. A straightforward application of the mean value theorem then gives $\hat{a}_{i}<a_{i}$. Hence, a utility-maximizing person who considers status concern to be a negative attribute will have a negatively biased perception of their own concern for status, but the degree of bias is limited by the self-image effects of dishonesty. The same arguments can be made for a positive bias in the perception of one's own concerns for the environment.

According to psychologists, such as Gilovich (1991) and Baumeister (1998), self-deception does not arise from a conscious or deliberate process. ${ }^{7}$ Therefore we do not assume in our study that people deliberately report dishonestly. Consequently, we still expect that the status perception of those who are genuinely more concerned with status to be higher than that of those who are genuinely less concerned. However, it does not follow that those who are more concerned with status would perceive that this was the case.

\footnotetext{
${ }^{7}$ If it did then it would not work. It does not make sense to say: "I have decided to believe that I am smarter than I am, because I get increased utility from this belief.”
} 
Status concern typically implies that people not only care about their own consumption, but also about that of others, and the same might be argued for selfimage effects per se. Maybe, in terms of self-image, it is not only important to be generous, socially responsible etc., but it is also important to be more generous and more socially responsible than others. If so, we can instead write the self-image function as follows

$$
S=s(\hat{a}, \hat{r}, h) \equiv s\left(\hat{a}, \hat{a} / \hat{a}_{\text {mean }}, h\right) .
$$

where $\hat{a}_{\text {mean }}$ is a vector of the individual's perception of how much various attributes matter to others, on average. Hence, the utility is now also a function of the individual's perceived concern relative to the average perceived concern of others. For example, since it is now bad to be more concerned about status than others, it is not only the absolute level that matters. The first order conditions with respect to $\hat{a}_{i}$ and $\hat{a}_{i, \text { mean }}$ imply

$$
-\frac{\partial s}{\partial \hat{a}_{i}}-\frac{\partial s}{\partial \hat{r}_{i}} \frac{1}{\hat{a}_{\text {mean }}}=\frac{\partial s}{\partial h} \frac{\partial h}{\partial d_{i}}
$$

and

$$
\frac{\partial s}{\partial \hat{r}_{i}} \frac{\hat{a}_{i}}{\left(\hat{a}_{i, \text { mean }}\right)^{2}}=\frac{\partial s}{\partial h} \frac{\partial h}{\partial d_{i}}
$$

The main implication here, as opposed to above, is that people will not only bias their status concern downwards, but they will also bias the perception of the status concern of others upwards. Given that the latter type of bias exists, whose perceptions would be most affected by such a bias? We can think of two possible effects, both of which go in the same direction. First, those who do not believe that status concern is such a bad thing are more likely to be more concerned about status, and answer 
correspondingly; and if they do not think that concern for status is as bad as others think they will also have smaller incentives to bias their response concerning the status perception of others. Indeed, in the case where a person is perfectly neutral towards status concern, there is no reason to bias either their own status perception or that of others. Second, (which is possible to formalise based on an extension of the model above) given a degree of internal honesty, it is also possible that the goodness norm is affected by your own preferences and behaviour. Obviously, those who are greatly concerned with status would suffer more from a norm in which status concern is bad, than those who are completely unaffected by status. Indeed, for the latter, the norm may even increase utility, since they know that they are much less concerned than others (which is good). In this case, one can argue that those who are greatly concerned with status have an incentive to perceive the norm (one can think of a moderating honesty norm here as well) as being weaker than others perceive it to be; cf. Ng and Wang (2001). And if this is the case, they have less incentive to bias the status concern of others. Both of these explanations predict that those who are more concerned with their own status will exaggerate the concern of others to a lesser degree. The same arguments, in reverse, can be applied to environmental concern. These predictions will be tested in the empirical analysis.

Note that actual behaviour, not just stated attitudes, will be affected by selfimage through equation (3). Assume that you like all the attributes of a BMW, including (of course) the associated status value, but that you do not like to see yourself as a person who cares much for status. It is possible, then, that this self-image effect will make you decide not to buy a BMW after all but to buy a VW instead. However, contrary to statements of attitudes, there is now one more cost element of self-deception, namely the welfare loss of having a car for which the attributes are 
non-optimal for you (the VW instead of the BMW). Consequently, one would expect that self-image effects to affect attitudes and perceptions more than actual behaviour.

\section{Survey Results}

A survey on transport-related issues was mailed to 2500 randomly selected individuals aged between 18 and 65 years in Sweden during spring 2001; the response rate was $62 \%$. For the purpose of this paper we focused on the purchase of a privately owned car, since cars are often considered to be important status symbols, but also because they may signal environmental awareness (or the absence of it). Furthermore, car expenses typically constitute a considerable share of the household budget. To measure the strength of preferences regarding the car's characteristics, in which we included safety, environmental friendliness, look, motor power, comfort, space, fuel consumption and reliability, we used a four level scale taking on the ordinal levels of very important, fairly important, fairly unimportant and not important at all. We frame the questions regarding the characteristics of a car both in terms of how they would value these attributes if they were about to buy a car for themselves as well as how they believed others would value the same attributes. In addition we also collected socio-economic characteristics of the respondents and information regarding their ownership and usage of private cars. Due to incomplete responses mainly on socioeconomic questions, the sample size analysed is 1300 for how they would value these attributes themselves, and 1288 for how they believed others would value the same attributes.

\subsection{Self-reported attribute importance}


The respondents were first asked how they would value the above-mentioned attributes if they were about to buy a car for themselves. Table 1 summarises the preferences for these attributes. In order to simplify comparisons we also cardinalized the responses by using an 'importance-index'. The mean is calculated by using the following values on the levels; very important $=3$, fairly important $=2$, fairly unimportant $=1$, and completely unimportant $=0 .{ }^{8}$

>> Table 1

From the results it appears to follow that status value is by far the least important of all attributes. Instead, the most important ones are fuel consumption, reliability and safety. Moreover, people seem to be quite concerned about the environmental performance as well. From this one might be tempted to conclude that cars, after all, are not particularly positional, and that people are almost exclusively concerned with the 'real' characteristics of the car instead. However, given the possibility of selfdeception as discussed above, it could also be that the self-reported concerns in Table 1 are systematically biased in accordance with this self-deception.

\subsection{Attribute importance for others}

To test the hypothesis of biased self-reported perceptions, we asked half of the sample how much they believed that others in their neighbourhood would value, on average, the same characteristics. As we see in Table 2, the average concern for status is

\footnotetext{
${ }^{8}$ This cardinalization is of course not without problems, and is presented solely to simplify comparisons. For example, it implicitly assumes that the difference between very important and fairly important is the same as between fairly unimportant and completely unimportant, which is not at all obvious. The subsequent econometric analysis, however, is based solely on the ordinal information. However, even the ordered-probit estimator contains an implicit cardinalization, even though it is not stated explicitly beforehand; see e.g. Van Praag and Ferrer-i-Carbonell (2003).
} 
clearly larger here, while concern for the environment and safety are considerably lower. The other half was asked to judge how the average Swede ("averageSvensson”) would value these characteristics. Here we see an even larger concern for status and a lower concern for safety. But which of these cases give the most reliable description of the concern for status and the environment? On the one hand, one may argue that the respondents themselves have the most information about their own preferences, and hence that their expressed preferences are more likely to be reliable. But while limited information does provide an argument for lower accuracy in the latter estimates, it does not explain the systematic difference between the cases. The self-image argument, on the other hand, implies that the individual has 'incentives' to bias their own concern for status and the environment in the observed directions.

>>> Table 2

\subsection{Car-dealers' perceptions of attribute importance}

In order to gain further insights about underlying preferences and possible biases, we randomly selected a sample of 100 car-dealers in Sweden and conducted a telephone interview. They were asked questions about how the average Swede would value the same attributes. Due to incomplete responses, the sample used in the analysis contained 83 car-dealers and the results of the interviews are reported in Table 3. It is presumed that car dealers have a more accurate perception of this issue than people in general, since part of their success as car dealers depends on their ability to judge what people really care about when buying a car.

>>> Table 3

The results show that car-dealers judged the status-value of a car to be of less importance than several other attributes. This might be interpreted as a certain degree 
of support for conventional micro-economic theory, where effects of relative consumption are ignored. However, it appears reasonable that many people derive utility from driving a safer, more powerful, more beautiful, and even a more environmentally friendly car than others, even though we may not normally interpret that as status concern. So, from the results we cannot conclude that the absolute features of cars are more important than the relative ones.

The results also indicate that car dealers believe that people, on average, care more about status than they believe, but less about it than they believe others do. This supports the hypothesis that people's self-image depends on relative status concern, as in equation (5), i.e. that it is important not to be more concerned about status than others. Note that effects of preference falsification, i.e. that people in general conversations may not admit that they are as concerned about status as they are, would tend to bias general perceptions of other people's preferences in the opposite direction. Since only the net effect is measured, this suggests that the importance of being less concerned about status than others is even larger than seems to be implied when comparing Tables 1 and 2.

However, we do not see this pattern with environmental concern. Indeed, car dealers state that people on average are less concerned with environmental performance than people, on average, claim. This is perfectly consistent with the implications of preference falsification discussed above, and if this effect is sufficiently strong, it may mask existing relative environmental concern. Hence, we cannot rule out that people may consider it important not only to see themselves as being environmentally concerned per se, but to see themselves as being more environmentally concerned than others as well. 
Note that influence of preference falsification here does not mean that respondents falsify the expressed preferences in the survey; indeed, we assume that they do not, since the anonymous survey does not provide any obvious incentive to do so. But people do have incentives to falsify preferences for the environment in their daily life, if it is politically incorrect not to care about the environment, and the respondents base their perceptions of other people’s environmental concern partly on their memory of other people's previously expressed concerns. Again, only the net effect is measured, and if it is important to be more concerned about the environment than others, then effects of preference falsification are even larger than the results seem to imply.

Why do we find a different pattern for the status concern of others in comparison with their environmental concern? Possibly, it is considered more politically incorrect not to care about the environment, on average, than it is to be concerned about status; whereas in terms of self-image, it might be more important not to be more concerned about status than others than it is to be more concerned about the environment.

\section{Econometric analysis}

Since the empirical analysis focuses on ordered discrete variables, representing selfreported concerns for different attributes on a four-level scale, an appropriate econometric approach is to use an ordered probit model. This approach is based on the idea of a latent unobservable variable, $R_{i}^{*}$, representing, in our case, individuals’ perceived importance for an attribute $i$ with the following structure:

$$
R_{i}^{*}=\delta^{\prime} X+\varepsilon
$$


where $\delta$ is a vector of parameters to be estimated, $X$ is a vector of explanatory variables, $\varepsilon$ is a normally distributed error term with zero mean and constant variance, and where the reported attribute importance is

$$
\begin{aligned}
& R_{i}=0 \quad \text { if } \quad R_{i}^{*} \leq \alpha_{1}, \\
& R_{i}=1 \quad \text { if } \quad \alpha_{1}<R_{i}^{*} \leq \alpha_{2}, \\
& R_{i}=2 \text { if } \alpha_{2}<R_{i}^{*} \leq \alpha_{3}, \\
& R_{i}=3 \text { if } R_{i}^{*}>\alpha_{3},
\end{aligned}
$$

where $R_{i}=0$ indicates not important at all increasing to $R_{i}=3$ indicating very important; $\alpha$ is a vector of the cut-off points to be estimated simultaneously.

\subsection{Between-sample differences}

In order to test whether the observed differences between the samples are statistically significant, we ran an ordered Probit regression where the reposted concern is explained by whose concern it is, i.e. their own, their neighbours' or the average Swede's; hence car dealers' perceptions of the average Swede constitute the base case. The results are presented in Table 4.

>>> Table 4

The results show that, relative to the perception of car dealers, people's own selfreported perception of their preferences differ significantly and positively for environmental performance and safety, and negatively for look and status, which is consistent with the theoretical predictions. All remaining differences are statistically insignificant at 5\% level.

Large differences are also observed for the perception of other people's preferences for several attributes. In particular we see that the differences between 
status and environmental concern discussed above are highly significant. In addition, people seem to under-estimate other people's concern for comfort, space and reliability, and over-estimate their concern for motor power. A possible reason is that the former attributes are seen as more 'rational' and that people under-estimate others' concern for them to improve their own relative rationality, which is good for their self-image, and vice versa for motor power. However, in addition to the self-image and preference-falsification effects discussed, there are of course other possible explanations for systematic bias, e.g. based on cognitive limitations as pointed out by Gilovich (1991).

\subsection{Status-value}

The results from the regressions for status-value as explained by socio-economic characteristics are presented in Table 5, divided on self-reported concern and that reported for others. The signs of the coefficients for personal status concern are generally expected, or at least reasonable, and support the assumption that on average people do try to respond honestly and that the imposed bias is not conscious.

>> Table 5

Individuals who drive a new car ( $<5$ years old), males and citizens of small towns are significantly more concerned about status, whereas the old and people educated at university appear to be significantly less concerned. However, this should not be taken as evidence that women and university educated people are generally less concerned with status; rather, it indicates that these groups get relatively more status from the consumption of other goods. For example, having an excessively fancy car among academics may signal shallowness rather than personal success; cf. Bourdieu (1984) and Douglas and Isherwood (1996). There are many potential explanations for 
the inter-generational and rural-urban differences found. For example, it is possible that there is a stronger instrumental benefit from an evolutionary perspective for a young person to care about status, e.g. since social networks tend to become more fixed with age. The small-town effect may reflect the fact that for status effects to be important you must have a number of people with whom you can compare yourself (and your car), and at the same time those others must not be anonymous strangers to you (as they might be in bigger cities).

Alternatively, there may be several possible equilibria within each group, and the obtained differences may simply reflect different equilibria. It is well-known from the literature on informational and reputational cascades that even small initial differences may cause large differences in eventual outcome; see e.g. Kuran (1998b) and Sunstein (2003). However, neither our theoretical model nor our data allow us to further analyse dynamic effects like these.

Regarding the stated concern for others it was hypothesized that the pattern would be reversed so that those groups that are more concerned with personal status would judge the average status concern to be relatively small in comparison with what other people thought average status concern to be. The pattern is largely in accordance with this hypothesis; for most significant parameter estimates of personal status concern we see the opposite sign for the concern of others. For example, drivers of new exclusive cars and males respond that people in general are less concerned with status than other people think they are.

\subsection{Environmental performance}

The results shown in Table 6 indicate that females, old people, and owners of new cars are significantly more concerned about the environmental performance of the car. 
That females are more environmentally concerned may indicate that they are more concerned with others than men, which if so is consistent with Eckel and Grossman (1998), who showed that females typically donate much more than men in so-called dictator games, and with Johansson-Stenman and Svedsäter (2003), who found that women were willing to contribute more to WWF-projects than men. That older people appear to be more concerned with the environment may possibly reflect that social responsibility is more important for them than for younger people, and it is consistent with List (2003) who in a number of field experiments found that the strength of social preferences increases with age, corrected for other variables. Owners of new cars seem to be more environmentally concerned, which may be explained by the fact that those who are more concerned will have bought newer cars, since these are evidently superior in environmental terms. However, it may also partly be explained by rationalization: if you have bought a new car, and newer cars are better for the environment, than it may be good for your self-image to believe that the new car was bought partly because of your environmental concern. The parameter associated with household income ${ }^{9}$ is significantly negative, suggesting that environmental performance may not be seen as a luxury, as it is sometimes proposed to be.

>> Table 6

The parameters associated with other people’s environmental concern are mostly insignificant, with old and university-educated people as the exceptions. Hence, the hypothesis derived from concern about relative environmental concern is again rejected.

\footnotetext{
${ }^{9}$ In order to compare income between households, we employ the equivalence scale used by the National Tax Board (RSV) in Sweden. The scale assigns the first adult the value of 0.95, the following adults are set at 0.7 and each child at 0.61 units.
} 
How can we explain the negative parameter for university-education? Given that we accept that people's perception of others' environmental concern is biased upwards due to preference falsification, from conversations with others prior to the survey, it is reasonable to believe that some people have a greater ability than others to reveal the preference falsifications of other people. Since university education is in part about independent and critical thinking, it is possible that higher levels of education improve this ability. Admittedly, however, this view of university education may be too optimistic and there are of course other possible explanations.

\section{Discussion and conclusion}

The present paper provides survey evidence that people do care about both status value and environmental performance when they are about to buy a car, and that we tend to be more concerned with status, and less concerned with the environment, than we would admit even to ourselves. Even though these findings are all inconsistent with conventional textbook theory, they are consistent with a simple modification of the standard theory, where self-image is an element of the utility function, e.g. as in the model by Akerlof and Kranton (2000, 2002). Hence, people derive utility from having a good self-image, and this self-image is determined in part by the perception of one's own preferences. On average, people consider it bad to be concerned about status and good to be concerned about the environment. The suggested self-image model also includes an honesty effect that moderates the perception bias. It is possible, of course, that the degrees to which status concern is perceived to be a social ill, and environmental concern a social good, vary culturally. It would therefore be interesting to see similar studies undertaken in other countries, e.g. in the United States. 
We have also found evidence that people’s perceptions of others' preferences are biased for two reasons (in opposite directions): $i$. People want to see themselves as better than others, implying biased perceptions of others in what is perceived to be a negative direction, and ii. People are influenced by preference falsification prior to the survey situation. For example, people will in daily conversation give the impression that they are much more concerned about the environment than they actually are. Consequently, people may believe that others are more concerned than they are, or, more generally, have preferences more in accordance with social norms than they do.

The systematic biases that occurred in the survey situation have been assumed to exist due to self-image effects rather than self-presentation effects (through preference falsification), since the survey was perfectly anonymous. However, it cannot be ruled out that some respondents did not perceive the survey to be perfectly anonymous, and that they have perceived that they communicated with someone who could, at least partly, observe them. If so, parts of what has been interpreted as selfimage effects may in fact be self-presentation effects. We think it is difficult to construct a set-up in surveys or experiments that completely eliminates either selfpresentation or self-image effects. What could easily be done in future research, however, is to increase the incentives for preference falsification by making the survey less anonymous, e.g. through personal interviews, and then compare the results obtained. The difference would then presumably depend primarily on selfpresentation effects, i.e. preference falsification.

Nevertheless, self-image and self-presentation effects may be difficult to disentangle at an even more fundamental level. First, a positive self-image may be instrumental in being perceived positively by others. It is cognitively more demanding 
to present a very different picture of one's self to others, and it is also more difficult to uncover liars who believe they are telling the truth; cf. Frank (1988). This is one reason why a positive self-image may have had (and perhaps has) a large evolutionary value. $^{10}$ Second, a positive self-presentation may be instrumental in obtaining a positive self-image as well. If you succeed in convincing others that you are very concerned about the environment, others will treat you as a person who is indeed very concerned about the environment. And such treatment by others will per se affect your self-image.

The findings here also suggest that one should be careful when interpreting survey responses in general, since these may be largely influenced by self-image considerations. Although actual decisions are also affected by such considerations, they may be exaggerated in a survey context since the 'cost' of improving your selfimage is then lower than in real decisions.

There is a huge, theoretical as well as empirical, literature discussing different methods of and problems on how to elicit the general public's preferences for various goods. The main conclusion of the current paper is that we have limited knowledge also about our own preferences, and that, in particular, there are systematic observable patterns that describe the discrepancy between our preferences on the one hand, and our perception of our preferences on the other. In the present paper we have for empirical reasons limited the analysis to a static perspective. Nevertheless, we encourage future research both on the processes under which identity formation takes place, and also on how public policy may affect, or more generally interact with, these processes.

\footnotetext{
${ }^{10}$ Benabou and Tirole (2002) discuss another reason namely that a positively biased self-image may help people to overcome their myopic self-control problems.
} 


\section{References}

Aaron, H. J., 1994. Public policy, values and consciousness. Journal of Economic Perspectives 8, 3-21.

Ackerman, Frank, 1997, Why Do We Recycle? Markets, Values, and Public Policy (Island Press, Washington, D.C.)

Akerlof, G. A., Dickens, W. T., 1982. The Economic Consequences of Cognitive Dissonance. American Economic Review 72, 307-319.

Akerlof, G., Kranton, R. E., 2000. Economics and identity. Quarterly Journal of Economics 115, 715-753.

Akerlof, G., Kranton, R. E., 2002. Identity and Schooling: Some Lessons for the Economics of Education. Journal of Economic Literature 40, 1167-1201.

Alpizar, F., Carlsson, F., Johansson-Stenman, O., 2002. How Much do We Care About Absolute Versus Relative Income and Consumption. Journal of Economic Behavior and Organization, forthcoming.

Aronson, E., 1992. The Return of the Repressed: Dissonance Theory Makes a Comeback. Psychological Inquiry 3, 303-311.

Basmann, R. L., Molina, D. J., Slottje, D. J., 1988. A Note on Measuring Veblen's Theory of Conspicuous Consumption. Review of Economics and Statistics 70, 531-535.

Baumeister, R., 1998. The self', In: D. Gilbert, S. Fiske, and G. Lindzey (Eds.), Handbook of Social Psychology. McGraw Hill, Boston pp. 680-740.

Benabou, R., Tirole, J., 2002. Self-confidence and personal motivation. Quarterly Journal of Economics 117, 871-915.

Benabou, R., Tirole, J., 2003. Intrinsic and extrinsic motivation. Review of Economic Studies 70, 489-520. 
Bourdieu, Pierre, 1984, Distinction: A Social Critique of the Judgement of Taste (Routledge, London).

Brekke, Kjell Arne, Howarth, Richard B., 2002, Affluence, Well-being and Environmental Quality (Edward Elgar, Cheltenham).

Brekke, K. A., Kverndokk S., Nyborg, K., 2002. An economic model of moral motivation', Journal of Public Economics 87, 1967-1983.

Brownstone, D., Bunch, D., Train, K., 2000. Joint mixed logit models of stated and revealed preferences for alternative-fuel vehicles. Transportation Research B 34, 315-338.

Brownstone, D., Train, K., 1999. Forecasting new product penetration with flexible substitution patterns. Journal of Econometrics 89, 109-129.

Chao, A., Schor, J. B., 1998. Empirical Tests of Status Consumption: Evidence from Women's Cosmetics. Journal of Economic Psychology 19, 107-131.

Douglas, Mary, Isherwood, Baron, 1996, The World of Goods: Towards an Anthropology of Consumption (Routledge, London and New York).

Easterlin, R.A., 1995. Will Raising the Incomes of All Increase the Happiness of All?. Journal of Economic Behavior and Organization 27, 35-47.

Eckel, C. C., Grossman, P. J., 1998. Are Women Less Selfish Than Men? Evidence from Dictator Experiments. Economic Journal 108, 726-735.

Elster, J., 1989. Social Norms and Economic Theory. Journal of Economic Perspectives 3, 99-117.

Elster, Jon, 1999, Alchemies of the Mind: Rationality and the Emotions (Cambridge University Press, Cambridge).

Ewing, G., Sarigöllü, E., 1998. Car fuel-type choice under travel demand management and economic incentives. Transportation Research D 3, 429-444. 
Frank, Robert H., 1985a, Choosing the Right Pond: Human Behavior and the Quest for Status (Oxford University Press, New York).

Frank, R.H., 1985b. The Demand for Unobservable and Other Nonpositional Goods. American Economic Review 75, 101-116.

Frank, Robert H., 1988, Passions Within Reasons (W.W. Norton, New York and London).

Frank, Robert H., 1999, Luxury Fever: Money and Happiness in an Era of Excess (The Free Press, New York).

Gilovich, Thomas, 1991, Why We Know What Isn’t So (The Free Press, New York).

Hirsch, Fred, 1976, Social Limits to Growth (Harvard University Press, Cambridge).

Holländer, H., 2001. On the Validity of Utility Statements: Standard Theory Versus Duesenberry's. Journal of Economic Behavior and Organization 45, 227-249.

Johansson-Stenman, O., Carlsson, F., Daruvala, D., 2002. Measuring Future Grandparents' Preferences for Equality and Relative Standing. Economic Journal 112, 362-383.

Johansson-Stenman, O., Svedsäter, H., 2003. Self-image and choice experiments: Hypothetical and actual willingness to pay. S-WOPEC working paper no. 94, Göteborg University.

Kooreman, P., Haan, M., 2001. Three price anomalies in the used-car market'. University of Groningen, working paper.

Köszegi, B., 2001. Ego utility, overconfidence and task choice. University of California, Berkeley, working paper.

Kuran, T., 1987. Preference Falsification, Policy Continuity and Collective Conservatism. Economic Journal 97, 642-665.

Kuran, T., 1990. Private and Public Preferences. Economics and Philosophy 6, 1-26. 
Kuran, Timur, 1995, Private Truths, Public Lies: The Social Consequences of Preference Falsification (Harvard University Press, Harvard).

Kuran, T., 1998a. Moral overload and its alleviation, In: A. Ben-Ner and L. Putterman (Eds.), Economics, Values and Organization. Cambridge University Press, Cambridge.

Kuran, T., 1998b. Ethnic Norms and Their Transformation through Reputational Cascades. Journal of Legal Studies 27, 623-659.

List, J., 2003. Young, Selfish, and Male: Field Evidence of Social Preferences. Economic Journal 114, 121-149.

Loewenstein, G., 1999. Because It Is There: The Challenge of Mountaineering... for Utility Theory. Kyklos 52, 315-343.

Ng, Y.-K., Wang, J., 2001. Attitude Choice, Economic Change, and Welfare. Journal of Economic Behavior and Organization 45, 279-291.

Oswald, A.J., 1997. Happiness and Economic Performance. Economic Journal 107, 1815-1831.

Rabin, M., 1994. Cognitive dissonance and social change. Journal of Economic Behavior and Organization 23, 177-194.

Slovic, P., 1995. The Construction of Preference. American Psychologist 50, 364-371.

Solnick, S., Hemenway, D., 1998. Is more always better?: A survey on positional concerns. Journal of Economic Behavior and Organization 37, 373-83.

Sunstein, Cass R., 2003, Why Societies Need Dissent (Harvard University Press, Cambridge and London).

Taylor, S. E., Brown, J. D., 1994. Positive illusions and well-being revisited: Separating fact from fiction. Psychological Bulletin 116, 21-27. 
van Praag, Bernard, Ferrer-i-Carbonell, Ada, 2003, Happiness Quantified: A Satisfaction Calculus Approach, forthcoming.

Veblen, Thorstein, 1899, The Theory of the Leisure Class (Macmillan, New York).

Weiss, Y., Fershtman, C., 1998. Social status and economic performance: A survey. European Economic Review 42, 801-820.

Young, P., 1998. Social norms and economic welfare. European Economic Review 42, 821-830. 
Table 1: How important are the different characteristics for you?

\begin{tabular}{llllll}
\hline & $\begin{array}{l}\text { Very } \\
\text { important }\end{array}$ & $\begin{array}{l}\text { Fairly } \\
\text { important }\end{array}$ & $\begin{array}{l}\text { Fairly } \\
\text { unimportant }\end{array}$ & $\begin{array}{l}\text { Not } \\
\text { important } \\
\text { all }\end{array}$ & $\begin{array}{l}\text { Importance } \\
\text { index (0-3) }\end{array}$ \\
\hline $\begin{array}{l}\text { Safety } \\
\text { Environmental }\end{array}$ & $85 \%$ & $15 \%$ & $1 \%$ & $0 \%$ & 2.8 \\
performance & $45 \%$ & $47 \%$ & $7 \%$ & $1 \%$ & 2.4 \\
Look & $20 \%$ & $51 \%$ & $26 \%$ & $3 \%$ & 1.9 \\
Motor power & $17 \%$ & $55 \%$ & $26 \%$ & $2 \%$ & 1.9 \\
Status & $6 \%$ & $21 \%$ & $47 \%$ & $26 \%$ & 1.1 \\
Comfort & $47 \%$ & $49 \%$ & $4 \%$ & $0 \%$ & 2.4 \\
Space & $44 \%$ & $48 \%$ & $8 \%$ & $0 \%$ & 2.4 \\
Fuel consumption & $60 \%$ & $36 \%$ & $4 \%$ & $0 \%$ & 2.5 \\
Reliability & $79 \%$ & $20 \%$ & $1 \%$ & $0 \%$ & 2.8 \\
\hline
\end{tabular}

Number of observations: 1300

Table 2: How important are the different characteristics for your neighbours (average-Swede)?

\begin{tabular}{llllll}
\hline & $\begin{array}{l}\text { Very } \\
\text { important }\end{array}$ & $\begin{array}{l}\text { Fairly } \\
\text { important }\end{array}$ & $\begin{array}{l}\text { Fairly } \\
\text { unimportant }\end{array}$ & $\begin{array}{l}\text { Not important } \\
\text { at all }\end{array}$ & $\begin{array}{l}\text { Importance } \\
\text { index (0-3) }\end{array}$ \\
\hline Safety & $57 \%$ & $39 \%$ & $3 \%$ & $0 \%$ & 2.5 \\
Environmental & $(59 \%)$ & $(37 \%)$ & $(3 \%)$ & $(0 \%)$ & $(2.6)$ \\
performance & $21 \%$ & $54 \%$ & $22 \%$ & $3 \%$ & 1.9 \\
& $(20 \%)$ & $(52 \%)$ & $(26 \%)$ & $(1 \%)$ & $(1.9)$ \\
Look & $28 \%$ & $53 \%$ & $18 \%$ & $2 \%$ & 2.1 \\
& $(34 \%)$ & $(54 \%)$ & $(11 \%)$ & $(1 \%)$ & $(2.2)$ \\
Motor power & $22 \%$ & $54 \%$ & $22 \%$ & $2 \%$ & 2.0 \\
Status & $(25 \%)$ & $(54 \%)$ & $(21 \%)$ & $(0 \%)$ & $(2.0)$ \\
& $23 \%$ & $41 \%$ & $30 \%$ & $6 \%$ & 1.8 \\
Comfort & $(30 \%)$ & $(48 \%)$ & $(20 \%)$ & $(2 \%)$ & $(2.1)$ \\
Space & $35 \%$ & $54 \%$ & $9 \%$ & $1 \%$ & 2.2 \\
& $(34 \%)$ & $(59 \%)$ & $(6 \%)$ & $(0 \%)$ & $(2.3)$ \\
Fuel consumption & $31 \%$ & $57 \%$ & $11 \%$ & $1 \%$ & 2.2 \\
& $(34 \%)$ & $(58 \%)$ & $(8 \%)$ & $(0 \%)$ & $(2.2)$ \\
Reliability & $47 \%$ & $42 \%$ & $9 \%$ & $1 \%$ & 2.4 \\
& $(56 \%)$ & $(38 \%)$ & $(6 \%)$ & $(0 \%)$ & $(2.5)$ \\
\hline
\end{tabular}

Number of observations: 1288

Table 3: Responses by car dealers to the question: How important are the different characteristics for the average-Swede?

\begin{tabular}{llllll}
\hline & $\begin{array}{l}\text { Very } \\
\text { important }\end{array}$ & $\begin{array}{l}\text { Fairly } \\
\text { important }\end{array}$ & $\begin{array}{l}\text { Fairly } \\
\text { unimportant }\end{array}$ & $\begin{array}{l}\text { Not important } \\
\text { at all }\end{array}$ & $\begin{array}{l}\text { Importance } \\
\text { index (0-3) }\end{array}$ \\
\hline $\begin{array}{l}\text { Safety } \\
\text { Environmental }\end{array}$ & $54 \%$ & $37 \%$ & $7 \%$ & $1 \%$ & 2.4 \\
performance & $5 \%$ & $43 \%$ & $45 \%$ & $7 \%$ & 1.5 \\
Look & $43 \%$ & $52 \%$ & $5 \%$ & $0 \%$ & 2.4 \\
Motor power & $13 \%$ & $52 \%$ & $34 \%$ & $1 \%$ & 1.8 \\
Status & $11 \%$ & $45 \%$ & $43 \%$ & $1 \%$ & 1.7 \\
Comfort & $49 \%$ & $49 \%$ & $1 \%$ & $0 \%$ & 2.5 \\
Space & $47 \%$ & $49 \%$ & $4 \%$ & $0 \%$ & 2.4 \\
Fuel consumption & $61 \%$ & $30 \%$ & $8 \%$ & $0 \%$ & 2.5 \\
Reliability & $78 \%$ & $18 \%$ & $4 \%$ & $0 \%$ & 2.7 \\
\hline
\end{tabular}

Number of observations: 83 
Table 4: Ordered Probit estimates for the importance of each attribute with dummy-variables for each sample as explanatory variables; reference group is car dealers' perception of the average-Swede's preferences.

\begin{tabular}{|c|c|c|c|c|c|c|c|c|c|}
\hline & Safety & $\begin{array}{c}\text { Environmental } \\
\text { performance }\end{array}$ & Look & Motor power & Status & Comfort & Space & $\begin{array}{c}\text { Fuel } \\
\text { consumption }\end{array}$ & Reliability \\
\hline Importance for & $0.966 * *$ & $1.357 * *$ & $-0.783 * *$ & 0.133 & $-0.759 * *$ & -0.127 & -0.146 & 0.015 & 0.063 \\
\hline you & $(0.135)$ & $(0.125)$ & $(0.130)$ & $(0.124)$ & $(0.121)$ & $(0.134)$ & $(0.132)$ & $(0.136)$ & $(0.154)$ \\
\hline Importance for & 0.136 & $0.690 * *$ & $-0.527^{* *}$ & $0.300 *$ & $0.206 * *$ & $-0.472 * *$ & $-0.461 * *$ & $-0.326^{*}$ & $-0.637 * *$ \\
\hline your neighbour & $(0.137)$ & $(0.127)$ & (0.133) & $(0.128)$ & $(0.125)$ & (0.138) & $(0.136)$ & (0.139) & $(0.156)$ \\
\hline Import. for the & 0.205 & $0.661^{* *}$ & $-0.295^{*}$ & $0.406 * *$ & $0.512 * *$ & $-0.394 * *$ & $-0.347 * *$ & -0.065 & $-0.558 * *$ \\
\hline average Swede & $(0.137)$ & $(0.127)$ & (0.133) & $(0.128)$ & $(0.125)$ & $(0.138)$ & $(0.136)$ & (0.139) & $(0.156)$ \\
\hline \multirow{2}{*}{$\alpha_{1}$} & -2.415 & -1.257 & -2.629 & -1.879 & -1.414 & -2.889 & -2.849 & -2.677 & -3.019 \\
\hline & $(0.174)$ & $(0.127)$ & (0.137) & $(0.131)$ & $(0.121)$ & $(0.162)$ & $(0.158)$ & $(0.160)$ & (0.181) \\
\hline \multirow{2}{*}{$\alpha_{2}$} & -1.579 & 0.016 & -1.378 & -0.422 & -0.161 & -1.831 & -1.624 & -1.608 & -2.230 \\
\hline & $(0.136)$ & $(0.120)$ & $(0.128)$ & $(0.121)$ & $(0.118)$ & (0.135) & $(0.132)$ & $(0.135)$ & (0.156) \\
\hline \multirow{2}{*}{$\alpha_{3}$} & -0.042 & 1.500 & 0.078 & 1.088 & 0.960 & -0.041 & 0.033 & -0.234 & -0.725 \\
\hline & $(0.129)$ & $(0.122)$ & $(0.126)$ & $(0.122)$ & (0.119) & $(0.130)$ & $(0.128)$ & $(0.132)$ & $(0.149)$ \\
\hline
\end{tabular}

Number of observations: 2671

** $\quad$ Statistically different from zero at $1 \%$ significance level.

* $\quad$ Statistically different from zero at $5 \%$ significance level. 
Table 5: Ordered Probit estimates for own and others' status concern.

\begin{tabular}{|c|c|c|}
\hline & Own status concern & Others' status concern \\
\hline Owner of a BMW, Mercedes or Porsche & $0.178(0.134)$ & $-0.396 * *(0.135)$ \\
\hline Owner of $<5$ years old car & $0.246 * *(0.064)$ & $-0.095(0.064)$ \\
\hline Male & $0.197 * *(0.061)$ & $-0.192 * *(0.062)$ \\
\hline Married & $-0.002(0.072)$ & $-0.027(0.072)$ \\
\hline Child & $0.124(0.068)$ & $0.135 *(0.068)$ \\
\hline \multicolumn{3}{|l|}{ Equivalent household income $(10,000$} \\
\hline SEK/month) & $0.088(0.059)$ & $-0.109(0.060)$ \\
\hline University-educated & $-0.316 * *(0.091)$ & $0.046(0.090)$ \\
\hline High-school educated & $0.052(0.083)$ & $0.004(0.083)$ \\
\hline Lives in a small town & $0.256 * *(0.086)$ & $0.053(0.087)$ \\
\hline Lives in a medium-sized town & $0.089(0.085)$ & $0.068(0.085)$ \\
\hline Lives in any of the three biggest cities & $0.135(0.086)$ & $0.048(0.086)$ \\
\hline Age & $-0.015 * *(0.003)$ & $0.008 * *(0.003)$ \\
\hline Average-Swede (neighbour as the base case) & & $0.316 * *(0.061)$ \\
\hline$\alpha_{1}$ & $-0.910(0.167)$ & $-1.524(0.175)$ \\
\hline$\alpha_{2}$ & $0.411(0.166)$ & $-0.268(0.169)$ \\
\hline$\alpha_{3}$ & $1.394(0.170)$ & $0.960(0.170)$ \\
\hline Number of observations & 1300 & 1288 \\
\hline
\end{tabular}

** $\quad$ Statistically different from zero at 1\% significance level.

* $\quad$ Statistically different from zero at $5 \%$ significance level.

Table 6: Ordered Probit estimates for own and others' environmental concern.

\begin{tabular}{|c|c|c|}
\hline & $\begin{array}{l}\text { Own environmental } \\
\text { concern }\end{array}$ & $\begin{array}{l}\text { Others' environmental } \\
\text { concern }\end{array}$ \\
\hline Owner of a BMW, Mercedes or Porsche & $-0.161(0.141)$ & $0.192(0.138)$ \\
\hline Owner of $<5$ years old car & $0.238 * *(0.069)$ & $0.021(0.065)$ \\
\hline Male & $-0.516 * *(0.066)$ & $-0.090(0.062)$ \\
\hline Married & $-0.096(0.077)$ & $-0.047(0.073)$ \\
\hline Child & $-0.062(0.072)$ & $0.034(0.069)$ \\
\hline \multicolumn{3}{|l|}{ Equivalent household income $(10,000$} \\
\hline SEK/month) & $-0.144 *(0.063)$ & $-0.090(0.062)$ \\
\hline University-educated & $-0.009(0.097)$ & $-0.238 * *(0.092)$ \\
\hline High-school educated & $-0.051(0.088)$ & $-0.084(0.084)$ \\
\hline Lives in a small town & $0.039(0.091)$ & $0.046(0.087)$ \\
\hline Lives in a medium-sized town & $0.075(0.090)$ & $0.048(0.086)$ \\
\hline Lives in any of the three biggest cities & $0.078(0.092)$ & $0.010(0.087)$ \\
\hline Age & $0.014 * *(0.003)$ & $0.008 * *(0.003)$ \\
\hline Average-Swede (neighbour as the base case) & & $0.316 * *(0.061)$ \\
\hline$\alpha_{1}$ & $-2.212(0.195)$ & $-1.524(0.175)$ \\
\hline$\alpha_{2}$ & $-1.303(0.177)$ & $-0.268(0.169)$ \\
\hline$\alpha_{3}$ & $0.317(0.175)$ & $0.960(0.170)$ \\
\hline Number of observations & 1300 & 1288 \\
\hline Statistically & iifican & \\
\hline
\end{tabular}

